\title{
PELABELAN SELIMUT BINTANG AJAIB SUPER PADA GRAF BINTANG
}

\author{
N. B. D. Mattiro' dan I W. Sudarsana ${ }^{2}$ \\ ${ }^{1,2}$ Program Studi Matematika Jurusan Matematika \\ Fakultas Matematika dan IImu Pengetahuan Alam Universitas Tadulako \\ Jalan Soekarno-Hatta Km. 09 Tondo, Palu 94118, Indonesia. \\ 1nuraenimattiro07@gmail.com, 2sudarsanaiwayan@yahoo.co.id
}

\begin{abstract}
Let $G=(V, E)$ be a simple graph. An edge covering of $G$ is a family of subgraphs $H_{1}, \ldots, H_{k}$ such that each edge of graph $E(G)$ belongs to at least one of the $H_{i}, 1 \leq i \leq k$ subgraphs. If each $H_{i}$ is isomorphic with the given graph $H$, then it is said that $G$ contains a $H$ - covering. The graph $\mathrm{G}$ contains a covering $H$ and $f$ the bijectif function $f: V(G) \cup E(G) \rightarrow(1,2,3, \ldots,|V(G)|+|E(G)|)$ is said an the $\mathrm{H}$-magic labeling of a graph $\mathrm{G}$ if for each subgraph $H^{\wedge}{ }^{\prime}=\left(V^{\prime}, E^{\prime}\right)$ of $G$ is isomorphic to $H$, so that $\sum_{v \in V\left(H^{\prime}\right)} f(V)+\sum_{e \in E\left(H^{\prime}\right)} f(E)$ is a constant. It is said that the graph $\mathrm{G}$ has a $H$-super magic if $f(V(G))=\{1,2,3, \ldots,|V(G)|\}$ in this case, the graph $\mathrm{G}$ which can be labeled with $H$ - magic is called the covering graph $H$ - magic. A star graph with $\mathrm{n}$ points is a graph with $n$ points and $n-1$ sides, where 1 point is $n-1$ degree and the other $n-1$ point has degree 1 denoted by $S_{n}$. This study aims to determine the presence of covering labeling for the $S_{3}$-super-magic star on the $S_{n}$ star graph. The research methodology is literature study. The results show that the $S_{n}$ star graph for $n \geq 4$ has $S_{3}-$ magic covering labeling with magic constants for all covering is $6 n-3$ and the $S_{3}$-super-magic covering labeling with magic constants for all covering is $4 n+3$.
\end{abstract}

Keywords : Covering H -Magic, Covering H -Super Magic, Star Graph.

\section{ABSTRAK}

Misalkan $G=(V, E)$ merupakan graf sederhana. Sebuah selimut sisi dari suatu graf $G$ adalah keluarga dari subgraf-subgraf $\mathrm{H}_{1}, \ldots, \mathrm{H}_{\mathrm{k}}$ sedemikian sehingga sebarang sisi dari graf $\mathrm{E}(\mathrm{G})$ berada paling sedikit satu dari subgraf-subgraf $\mathrm{H}_{\mathrm{i}}, 1 \leq \mathrm{i} \leq \mathrm{k}$. Jika setiap $\mathrm{H}_{\mathrm{i}}$ isomorfik dengan graf $\mathrm{H}$ yang diberikan, maka dikatakan bahwa $\mathrm{G}$ memuat sebuah selimut $H$. Graf $G$ memuat selimut $H$ dan $f$ sebuah fungsi bijektif $\mathrm{f}: \mathrm{V}(\mathrm{G}) \cup \mathrm{E}(\mathrm{G}) \rightarrow\{1,2,3, \ldots,|\mathrm{V}(\mathrm{G})|+|\mathrm{E}(\mathrm{G})|\}$ disebut pelabelan ajaib $\mathrm{H}$ dari suatu graf $\mathrm{G}$ jika untuk setiap subgraf $H^{\prime}=\left(V^{\prime}, E^{\prime}\right)$ dari $G$ isomorfik terhadap $H$, sehingga diperoleh $\sum_{v \in V\left(H^{\prime}\right)} f(V)+\sum_{e \in E\left(H^{\prime}\right)} f(E)$ adalah konstanta. Dikatakan bahwa graf $G$ memiliki $H$ selimut ajaib super jika $f(V(G))=\{1,2,3, \ldots,|V(G)|\}$. Dalam hal ini, graf $G$ yang dapat dilabeli dengan $\mathrm{H}$ - ajaib disebut graf selimut $\mathrm{H}$ - ajaib. Graf bintang (star) dengan n titik merupakan graf dengan banyak titik $n$ dan banyak sisi $n-1$, dimana 1 titik berderajat $n-1$ dan $n-1$ titik yang lain berderajat 1 yang dinotasikan dengan $S_{n}$. Penelitian ini bertujuan untuk menentukan adanya pelabelan selimut bintang $S_{3}-$ ajaib super pada graf bintang $S_{n}$. Metodologi penelitian adalah studi literatur. Hasil penelitian menunjukan bahwa 
graf bintang $S_{n}$ untuk $n \geq 4$ memiliki pelabelan selimut bintang $S_{3}$ - ajaib dengan konstanta ajaib untuk semua selimut adalah $6 n-3$ dan pelabelan selimut bintang $S_{3}$ - ajaib super dengan konstanta ajaib untuk semua selimut adalah $4 n+3$.

Kata kunci $\quad$ : Selimut H -Ajaib, Selimut H -Ajaib Super, Graf Bintang.

\section{PENDAHULUAN}

\subsection{Latar Belakang}

Pelabelan graf merupakan suatu topik dalam teori graf yang di perkenalkan oleh Leonhard Euler pada tahun 1736 sebagai upaya pemecahan masalah jembatan Konigsberg. Saat itu Leonhard Euler mencoba menemukan solusi untuk bisa menyeberangi jembatan tersebut tepat satu kali dari tempat berangkat sampai ke tempat semula. Untuk memecahkan masalah tersebut, Euler mempresentasikan daratan yang dihubungkan dengan jembatan adalah suatu titik (vertex) dan jembatan tersebut dinyatakan sebagai sisi (edge). Solusi inilah yang dikenal dengan Teori Graf.

Teori pelabelan graf banyak diaplikasikan dalam kehidupan sehari-hari, antara lain pada rute perjalanan, penjadwalan, dan jaringan listrik. Hingga saat ini pemanfaatan teori pelabelan graf sangat dirasakan peranannya, terutama pada sektor sistem komunikasi dan transportasi, navigasi geografis, radar, penyimpanan data computer, dan desain integrated circuit pada komponen elektronik dalam Ray (2013)[12].

Pelabelan merupakan pemetaan bijektif yang memetakan unsur himpunan titik dan unsur himpunan sisi ke bilangan asli yang disebut label. Pelabelan menurut domainnya dibagi menjadi tiga yaitu pelabelan titik, pelabelan sisi, dan pelabelan total. Pelabelan titik adalah pelabelan dengan domain himpunan titik, pelabelan sisi adalah pelabelan dengan domain himpunan sisi, dan pelabelan total adalah pelabelan dengan domain gabungan himpunan titik dan himpunan sisi. Saat ini terdapat beberapa jenis pelabelan antara lain pelabelan grafceful, pelabelan harmoni, pelabelan ajaib dan pelabelan anti ajaib.

Menurut Gallian (1997)[3], pelabelan ajaib pertama kali diperkenalkan oleh Sadlack pada tahun 1963, kemudian juga oleh Stewart pada pertengahan tahun 1960. Pada tahun 1970 dikembangkan juga oleh Kotzig dan Rosa sebagai pelabelan total titik ajaib, pelabelan total titik ajaib super, pelabelan total sisi ajaib, dan pelabelan total sisi ajaib super.

Pelabelan ajaib kemudian dikembangkan menjadi pelabelan selimut ajaib yang diperkenalkan pertama kali oleh Guitierrez dan Llado (2005)[4] membuktikan bahwa graf bipartite lengkap $K_{m, n}$ dapat diselimuti dengan selimut bintang ajaib $K_{1, n}$ dan graf bintang $K_{1, n}$ memiliki $K_{1, h}$ ajaib super. Kemudian Llado dan Moragas ( 2007 )[8] menemukan suatu selimut -cycle ajaib pada graf roda $W_{n}$ untuk $n$ ganjil, graf prisma dan graf buku. 
Hingga saat ini terdapat beberapa hasil penelitian terkait pelabelan selimut ajaib super seperti Selvagopal dan Jayanti (2008)[14] membuktikan untuk setiap bilangan bulat positif $n$, sebuah $k$ - polygonal lintasan dengan panjang $n$ memiliki $C_{k^{-}}$ajaib super. Ngurah et al. (2008)[11] melanjutkan penelitian tentang selimut-cycle ajaib pada graf tangga segitiga $T L_{n}$ dan graf buku $W_{n}$ serta Roswitha et al. (2013)[13] graf jahangir tergeneralisasi $J_{k, s}$, graf roda $W_{n}$ untuk $n$ Genap dan graf bipartit lengkap $K_{2, n}$. Maryati et al. (2015)[10] membuktikan beberapa pelabelan $P_{n}$-ajaib super dari siklus dengan beberapa sisi liontin dan sub divisinya. Secara komprehensif hasil penelitian terkait tersaji dalam [1], [2], [5]-[7], [9], [15]. Namun, penelitian terkait pelabelan selimut bintang ajaib super pada graf bintang belum pernah dilakukan. Berdasarkan hal tersebut, penulis tertarik untuk mengkaji tentang pelabelan selimut bintang ajaib super pada graf bintang $\left(S_{n}\right)$, khususnya pelabelan selimut $S_{k}$ dan $S_{n}$ itu sendiri.

\subsection{Rumusan Masalah}

Berdasarkan latar belakang diatas, maka rumusan masalah pada penelitian ini adalah bagaimana pelabelan selimut ajaib super berbentuk $S_{k}$ pada graf bintang $S_{n}$.

\subsection{Batasan Masalah}

Pada penelitian ini, obsevarsi akan dilakukan pada selimut bintang ajaib super berbentuk $S_{k}$ pada graf bintang $\left(S_{n}\right)$ untuk $k=3$ dan $n \geq 4$.

\section{METODE PENELITIAN}

Penelitian dilakukan sesuai prosedur penelitian sebagai berikut :

1. Memulai penelitian.

2. Studi literature

3. Menotasikan titik dan sisi pada graf bintang $S_{n}$ untuk $n \geq 4$.

4. Memformulasikan banyaknya selimut bintang yang berbentuk $S_{3}$ dari graf bintang $S_{n}$ untuk $n \geq 4$.

5. Memberikan label titik dan sisi pada graf bintang $S_{n}$ untuk $n \geq 4$.

6. Memperoleh konstanta selimut bintang $S_{3}$ pada graf bintang $S_{n}$.

7. Hasil dan Kesimpulan.

8. Selesai

\section{HASIL DAN PEMBAHASAN}

Pada bab ini akan di bahas hasil penelitian terkait pelabelan selimut ajaib dan selimut ajaib super pada graf bintang $\left(S_{n}\right)$. Pada penelitian ini, dibuat fungsi pelabelan total sisi ajaib dan fungsi pelabelan total sisi ajaib super untuk menentukan konstanta ajaib dari setiap selimut yang termuat pada graf $S_{n}$. Menotasikan titik dan sisi pada graf bintang $S_{n}$ seperti pada Gambar 2 . 


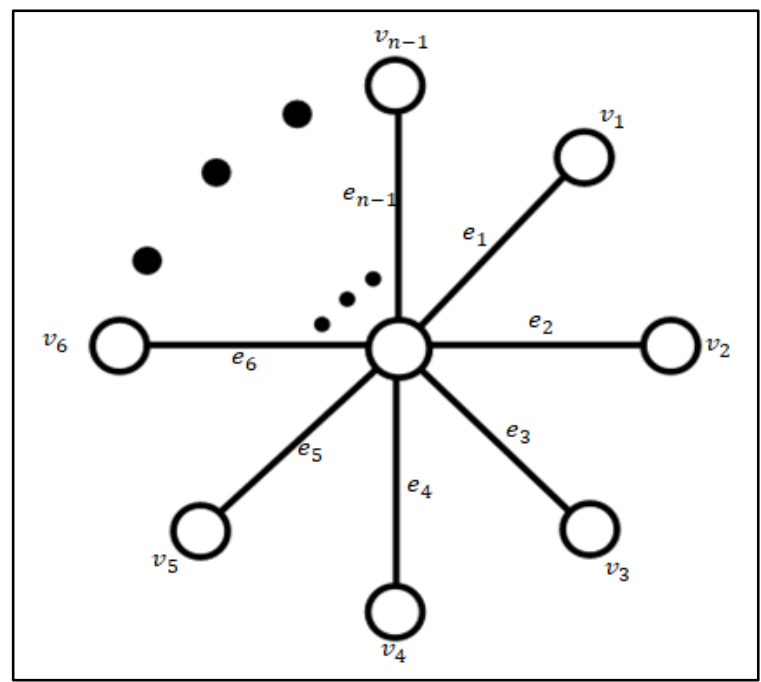

Gambar 2 : Penotasian Titik Dan Sisi Graf Bintang $S_{n}$

Berdasarkan Gambar 2, graf bintang $S_{n}$ memiliki himpunan titik dan sisi sebagai berikut:

$$
\begin{gathered}
V\left(S_{n}\right)=\{c\} \cup\left\{v_{i} \mid 1 \leq i \leq n-1\right\} \\
E\left(S_{n}\right)=\left\{e_{i}=c v_{i} \mid 1 \leq i \leq n-1\right\}
\end{gathered}
$$

dan di peroleh banyaknya titik graf $S_{n}$ adalah sebanyak $n$ sedangkan banyaknya sisi graf $S_{n}$ adalah sebanyak $n-1$. Sehingga jumlah banyaknya titik dan sisi pada graf $S_{n}$ adalah $2 n-1$.

\subsection{Pelabelan Selimut Bintang Ajaib Pada Graf Bintang}

Pelabelan selimut bintang ajaib pada graf bintang $\left(S_{n}\right)$ pada sub bab ini akan di sajikan pada Teorema berikut :

Teorema 1. Graf bintang dengan $n$ titik, $S_{n}$, memiliki pelabelan selimut bintang $S_{3}-$ ajaib untuk $\mathrm{n} \geq 4$.

Bukti:

Sebagai awal pembuktian akan di tunjukan bahwa banyak selimut $S_{3}$ pada $S_{n}$ dihitung dari jumlah banyak selimut pada setiap kelompok ke $-t$ dengan $1 \leq t \leq n-2$, dimana kelompok ke $-t$ memiliki banyaknya $n-t-1$, sehingga diperoleh banyak selimut $S_{3}$ pada $S_{n}$ sebagai berikut:

$$
\begin{array}{rl}
\sum_{t=1}^{n-2} n-t-1=\sum_{t=1}^{n-2} & n-\sum_{t=1}^{n-2} t-\sum_{t=1}^{n-2} 1 \\
= & n(n-2)-\left(\frac{(n-2)(n-2+1)}{2}\right)-(n-2) \\
& =n^{2}-2 n-\left(\frac{n^{2}-3 n+2}{2}\right)-n+2 \\
& =n^{2}-3 n+2-\left(\frac{n^{2}-3 n+2}{2}\right) \\
& =\frac{n^{2}-3 n+2}{2}
\end{array}
$$


Selanjutnya, selimut pada kelompok ke $-t$ sebanyak $n-t-1$ yang masing-masing selimutnya di notasikan dengan $c v_{t}, c v_{\frac{2 i-t^{2}-2 t n+2 n+3 t-2}{2}}$, di mana $\frac{2 t n-2 n-t^{2}-t+4}{2} \leq i \leq \frac{2 t n-t^{2}-3 t}{2}$ dan $1 \leq t \leq n-2$.

Selanjutnya, bentuk fungsi pelabelan pada titik $c, v_{i}$ dan sisi $e_{i}=c v_{i}$ sebagai berikut :

$$
\begin{gathered}
f(c)=2 n-1 \\
f\left(v_{i}\right)=2 n-1-i \text { untuk } 1 \leq i \leq n-1 \\
f\left(e_{i}\right)=f\left(c v_{i}\right)=i \text { untuk } 1 \leq i \leq n-1
\end{gathered}
$$

Kemudian bobot semua selimut $S_{3}$ pada graf $S_{n}$ untuk setiap kelompok ke - $t$ dapat di hitung dengan menggunakan persamaan berikut :

$$
\begin{aligned}
w\left(S_{3}^{i}\right) & =f(c)+f\left(v_{t}\right)+f\left(\frac{v_{2 i-t^{2}-2 t n+2 n+3 t-2}}{2}\right)+f\left(c v_{t}\right)+f\left(c v_{\frac{2 i-t^{2}-2 t n+2 n+3 t-2}{2}}\right) \\
& =2 n-1+(2 n-1-t)+2 n-1-\left(\frac{2 i-t^{2}-2 t n+2 n+3 t-2}{2}\right)+t+\left(\frac{2 i-t^{2}-2 t n+2 n+3 t-2}{2}\right) \\
& =6 n-3
\end{aligned}
$$

Dengan demikian, graf bintang $S_{n}$ memiliki $S_{3}$ - ajaib, dengan konstanta selimut ajaibnya adalah $6 n-3$, untuk $n \geq 4$.

\subsection{Pelabelan Selimut Bintang Ajaib Super Pada Graf Bintang}

Pelabelan selimut bintang ajaib pada graf bintang $\left(S_{n}\right)$ pada sub bab ini akan di sajikan pada Teorema 2 berikut :

Teorema 2. Graf bintang dengan $n$ titik, $S_{n}$, memiliki pelabelan selimut bintang $S_{3}$ - ajaib super untuk $\mathrm{n} \geq 4$.

Bukti :

Sebagai pembuktian awal telah di tunjukan pada Teorema 1 tentang banyaknya selimut $S_{3}$ pada graf bintang $S_{n}$, Selanjutnya, bentuk fungsi pelabelan pada titik $c, v_{i}$ dan sisi $e_{i}=c v_{i}$ sebagai berikut :

$$
\begin{gathered}
f(c)=1 \\
f\left(v_{i}\right)=i+1, \text { untuk } 1 \leq i \leq n-1 ; \\
f\left(e_{i}\right)=f\left(c v_{i}\right)=2 n-i, \text { untuk } 1 \leq i \leq n-1
\end{gathered}
$$

Kemudian bobot semua selimut $S_{3}$ pada graf $S_{n}$ untuk setiap kelompok ke - $t$ dapat di hitung dengan menggunakan persamaan yang sama pada Teorema 1 sebagai berikut :

$$
\begin{aligned}
w\left(S_{3}^{i}\right)= & f(c)+f\left(v_{t}\right)+f\left(\frac{v_{2 i-t^{2}-2 t n+2 n+3 t-2}}{2}\right)+f\left(c v_{t}\right)+f\left(c v_{\frac{2 i-t^{2}-2 t n+2 n+3 t-2}{2}}\right) \\
& =1+(t+1)+\left(\frac{2 i-t^{2}-2 t n+2 n+3 t-2}{2}\right)+1+2 n-t+2 n-\left(\frac{2 i-t^{2}-2 t n+2 n+3 t-2}{2}\right) \\
& =4 n+3
\end{aligned}
$$


Dengan demikian, graf bintang $S_{n}$ memiliki $S_{3}$ - ajaib super, dengan konstanta selimut ajaib supernya adalah $4 n+3$, untuk $n \geq 4$.

\subsection{Kasus Graf $S_{3}, S_{n}$ untuk $4 \leq n \leq 6$}

Pada sub bab ini akan ditunjukan contoh kasus pelabelan selimut bintang pada graf $S_{n}$ untuk $4 \leq n \leq 6$, sebagai berikut :

\subsubsection{Selimut Bintang $S_{3}$ Pada Graf $S_{4}$}

Banyak selimut $S_{3}$ pada graf $S_{n}$ adalah sebagai berikut :

$$
\begin{aligned}
\frac{n^{2}-3 n+2}{2} & =\frac{4^{2}-(3.4)+2}{2} \\
& =3
\end{aligned}
$$

Selanjutnya banyak selimut kelompok ke $-t$ dengan $1 \leq t \leq 2$ sebagai berikut :

- $\quad$ Banyak selimut kelompok ke -1 adalah $n-t-1=2$ dengan notasi selimut ke $-i$ untuk $1 \leq i \leq 2$ sebagai berikut :

$$
\begin{aligned}
& S_{3}^{1}=c v_{1}, c v_{2} \\
& S_{3}^{2}=c v_{1}, c v_{3}
\end{aligned}
$$

- $\quad$ Banyak selimut kelompok ke -2 adalah $n-t-1=1$ dengan notasi selimut ke $-i$ untuk $3 \leq i \leq 3$ sebagai berikut :

$$
S_{3}^{3}=c v_{2}, c v_{3}
$$

Selanjutnya memberikan label titik dan sisi seperti pada Gambar 3.

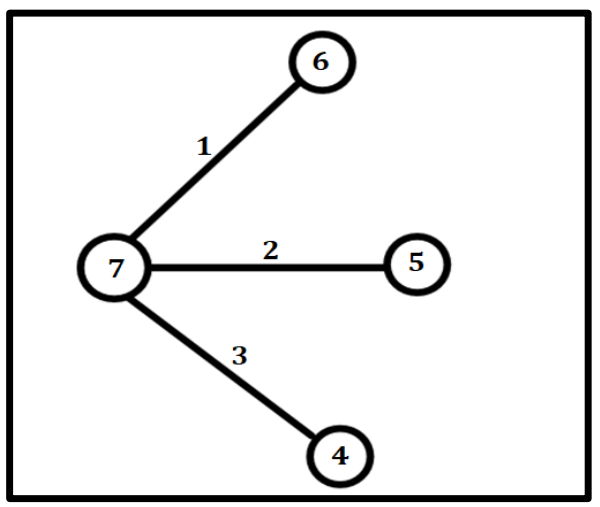

Gambar 3 : Pelabelan Total Selimut $S_{3}$-Ajaib Pada Graf $\mathrm{S}_{4}$ 


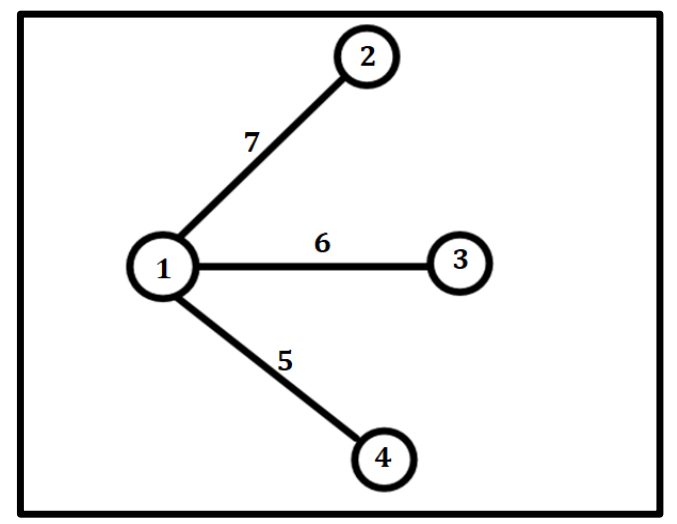

Gambar 4 : Pelabelan Total Selimut $S_{3}$ - Ajaib Super Pada Graf $S_{4}$

Perhatikan Gambar 3 dan Gambar 4 di atas bahwa titik diberi label dengan anggota himpunan untuk selimut ajaib $f(V)=\{1,2, \ldots, 2 n-1\}$ dan untuk selimut ajaib super $f(V)=\{1,2, \ldots, n\}$ dengan banyaknya titik $n=4$, sehingga di peroleh pelabelan total untuk selimut $S_{3}$ pada $S_{4}$ sebagai berikut :

- $\quad$ Pelabelan total ajaib

$$
\begin{array}{rlrl}
f(c)=7 & f\left(e_{1}\right)=1 \\
f\left(v_{1}\right)=6 & f\left(e_{2}\right)=2 \\
f\left(v_{2}\right)=5 & f\left(e_{3}\right)=3 \\
& f\left(v_{3}\right)=4 &
\end{array}
$$

- Pelabelan total ajaib super

$$
\begin{array}{rlrl}
f(c)=1 & f\left(e_{1}\right)=7 \\
f\left(v_{1}\right)=2 & f\left(e_{2}\right)=6 \\
f\left(v_{2}\right)=3 & f\left(e_{3}\right)=5 \\
& f\left(v_{3}\right)=4 &
\end{array}
$$

Setelah diberikan label titik dan sisi, kemudian menghitung bobot untuk setiap selimut $S_{3}$ pada $S_{4}$ seperti berikut :

- Pelabelan total ajaib

Kelompok ke -1 untuk $1 \leq i \leq 2$ :

$$
\begin{aligned}
W_{1}\left(S_{3}^{1}\right) & =f(c)+f\left(v_{1}\right)+f\left(v_{2}\right)+f\left(c v_{1}\right)+f\left(c v_{2}\right) \\
& =7+6+5+1+2 \\
& =21 \\
W_{2}\left(S_{3}^{2}\right) & =f(c)+f\left(v_{1}\right)+f\left(v_{3}\right)+f\left(c v_{1}\right)+f\left(c v_{3}\right) \\
& =7+6+4+1+3 \\
& =21
\end{aligned}
$$

Kelompok ke -2 untuk $3 \leq i \leq 3$ :

$$
\begin{aligned}
W_{3}\left(S_{3}^{3}\right) & =f(c)+f\left(v_{2}\right)+f\left(v_{3}\right)+f\left(c v_{2}\right)+f\left(c v_{3}\right) \\
& =7+5+4+2+3 \\
& =21
\end{aligned}
$$

- Pelabelan total ajaib super

Kelompok ke -1 untuk $1 \leq i \leq 2$ :

$$
\begin{aligned}
W_{1}\left(S_{3}^{1}\right) & =f(c)+f\left(v_{1}\right)+f\left(v_{2}\right)+f\left(c v_{1}\right)+f\left(c v_{2}\right) \\
& =1+2+3+7+6 \\
& =19
\end{aligned}
$$




$$
\begin{aligned}
W_{2}\left(S_{3}^{2}\right) & =f(c)+f\left(v_{1}\right)+f\left(v_{3}\right)+f\left(c v_{1}\right)+f\left(c v_{3}\right) \\
& =1+2+4+6+5 \\
& =19
\end{aligned}
$$

Kelompok ke -2 untuk $3 \leq i \leq 3$ :

$$
\begin{aligned}
W_{3}\left(S_{3}^{3}\right) & =f(c)+f\left(v_{2}\right)+f\left(v_{3}\right)+f\left(c v_{2}\right)+f\left(c v_{3}\right) \\
& =1+3+4+6+7 \\
& =19
\end{aligned}
$$

\subsubsection{Selimut Bintang $S_{3}$ pada graf $S_{5}$}

Banyak selimut $S_{3}$ pada graf $S_{n}$ adalah sebagai berikut:

$$
\begin{aligned}
\frac{n^{2}-3 n+2}{2} & =\frac{5^{2}-(3.5)+2}{2} \\
& =6
\end{aligned}
$$

Selanjutnya banyak selimut kelompok ke $-t$ dengan $1 \leq t \leq 3$ sebagai berikut :

- Banyak selimut kelompok ke -1 adalah $n-t-1=3$ dengan notasi selimut ke $-i$ untuk $1 \leq i \leq 3$ sebagai berikut :

$$
\begin{gathered}
S_{3}^{1}=c v_{1}, c v_{2} \\
S_{3}^{2}=c v_{1}, c v_{3} \\
S_{3}^{3}=c v_{1}, c v_{4}
\end{gathered}
$$

- Banyak selimut kelompok ke -2 adalah $n-t-1=2$ dengan notasi selimut ke $-i$ untuk $4 \leq i \leq 5$ sebagai berikut :

$$
\begin{aligned}
& S_{3}^{4}=c v_{2}, c v_{3} \\
& S_{3}^{5}=c v_{2}, c v_{4}
\end{aligned}
$$

- Banyak selimut kelompok ke -3 adalah $n-t-1=1$ dengan notasi selimut ke $-i$ untuk $6 \leq i \leq 6$ sebagai berikut :

$$
S_{3}^{6}=c v_{3}, c v_{4}
$$

Selanjutnya memberikan label titik dan sisi seperti pada Gambar 5.

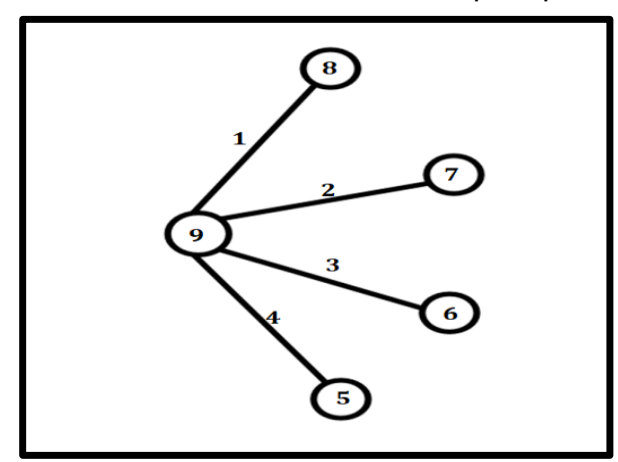

Gambar 5 : Pelabelan Total Selimut $S_{3}-$ Ajaib Pada Graf $\mathbf{S}_{\mathbf{5}}$ 


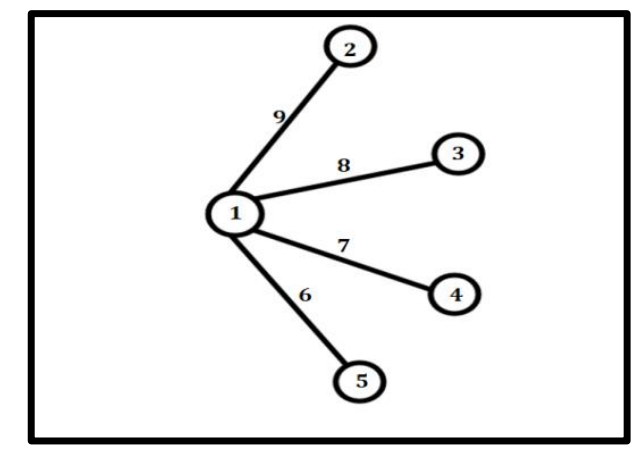

Gambar 6 : Pelabelan Total Selimut $S_{3}$-Ajaib Super Pada Graf $\mathbf{S}_{\mathbf{5}}$

Perhatikan Gambar 5 dan Gambar 6 di atas bahwa titik diberi label dengan anggota himpunan untuk selimut ajaib $f(V)=\{1,2, \ldots, 2 n-1\}$ dan untuk selimut ajaib super $f(V)=\{1,2, \ldots, n\}$ dengan banyaknya titik $n=5$, sehingga di peroleh pelabelan total selimut $S_{3}$ pada $S_{5}$ sebagai berikut :

- Pelabelan total selimut ajaib

$$
\begin{array}{cc}
f(c)=9 & f\left(e_{1}\right)=1 \\
f\left(v_{1}\right)=8 & f\left(e_{2}\right)=2 \\
f\left(v_{2}\right)=7 & f\left(e_{3}\right)=3 \\
f\left(v_{3}\right)=6 & f\left(e_{4}\right)=4 \\
f\left(v_{4}\right)=5 &
\end{array}
$$

- $\quad$ Pelabelan total selimut ajaib super

$$
\begin{array}{cr}
f(c)=1 & f\left(e_{1}\right)=9 \\
f\left(v_{1}\right)=2 & f\left(e_{2}\right)=8 \\
f\left(v_{2}\right)=3 & f\left(e_{3}\right)=7 \\
f\left(v_{3}\right)=4 & f\left(e_{4}\right)=6 \\
f\left(v_{4}\right)=5 &
\end{array}
$$

Setelah diberikan label titik dan sisi, kemudian menghitung bobot untuk setiap selimut $S_{3}$ pada $S_{5}$, seperti berikut :

- Pelabelan total ajaib

Kelompok ke -1 untuk $1 \leq i \leq 3$ sebagai berikut :

$$
\begin{aligned}
W_{1}\left(S_{3}^{1}\right) & =f(c)+f\left(v_{1}\right)+f\left(v_{2}\right)+f\left(c v_{1}\right)+f\left(c v_{2}\right) \\
& =9+8+7+1+2 \\
& =27 \\
W_{2}\left(S_{3}^{2}\right) & =f(c)+f\left(v_{1}\right)+f\left(v_{3}\right)+f\left(c v_{1}\right)+f\left(c v_{3}\right) \\
& =9+8+6+1+3 \\
& =27 \\
W_{3}\left(S_{3}^{3}\right) & =f(c)+f\left(v_{1}\right)+f\left(v_{4}\right)+f\left(c v_{1}\right)+f\left(c v_{4}\right) \\
& =9+8+5+1+4 \\
& =27
\end{aligned}
$$

Kelompok ke -2 untuk $4 \leq i \leq 5$ sebagai berikut :

$$
\begin{aligned}
W_{4}\left(S_{3}^{4}\right)= & f(c)+f\left(v_{2}\right)+f\left(v_{3}\right)+f\left(c v_{2}\right)+f\left(c v_{3}\right) \\
& =9+7+6+2+3 \\
& =27 \\
W_{5}\left(S_{3}^{5}\right) & =f(c)+f\left(v_{1}\right)+f\left(v_{3}\right)+f\left(c v_{1}\right)+f\left(c v_{3}\right) \\
& =9+7+5+2+4 \\
& =27
\end{aligned}
$$


Kelompok ke -3 untuk $6 \leq i \leq 6$ sebagai berikut :

$$
\begin{aligned}
W_{6}\left(S_{3}^{6}\right) & =f(c)+f\left(v_{2}\right)+f\left(v_{3}\right)+f\left(c v_{2}\right)+f\left(c v_{3}\right) \\
& =9+6+5+3+4 \\
& =27
\end{aligned}
$$

- Pelabelan total ajaib super

Kelompok ke -1 untuk $1 \leq i \leq 3$ sebagai berikut :

$$
\begin{aligned}
W_{1}\left(S_{3}^{1}\right) & =f(c)+f\left(v_{1}\right)+f\left(v_{2}\right)+f\left(c v_{1}\right)+f\left(c v_{2}\right) \\
& =1+2+3+9+8 \\
& =23 \\
W_{2}\left(S_{3}^{2}\right) & =f(c)+f\left(v_{1}\right)+f\left(v_{3}\right)+f\left(c v_{1}\right)+f\left(c v_{3}\right) \\
& =1+2+4+9+7 \\
& =23 \\
W_{3}\left(S_{3}^{3}\right) & =f(c)+f\left(v_{1}\right)+f\left(v_{4}\right)+f\left(c v_{1}\right)+f\left(c v_{4}\right) \\
& =1+2+5+9+6 \\
& =23
\end{aligned}
$$

Kelompok ke -2 untuk $4 \leq i \leq 5$ sebagai berikut :

$$
\begin{aligned}
W_{4}\left(S_{3}^{4}\right) & =f(c)+f\left(v_{2}\right)+f\left(v_{3}\right)+f\left(c v_{2}\right)+f\left(c v_{3}\right) \\
& =1+3+4+8+7 \\
& =23 \\
W_{5}\left(S_{3}^{5}\right) & =f(c)+f\left(v_{2}\right)+f\left(v_{4}\right)+f\left(c v_{2}\right)+f\left(c v_{4}\right) \\
& =1+3+5+8+6 \\
& =23
\end{aligned}
$$

Kelompok ke -3 untuk $6 \leq i \leq 6$ sebagai berikut :

$$
\begin{aligned}
W_{6}\left(S_{3}^{6}\right) & =f(c)+f\left(v_{3}\right)+f\left(v_{4}\right)+f\left(c v_{3}\right)+f\left(c v_{4}\right) \\
& =1+4+5+7+6 \\
& =23
\end{aligned}
$$

\subsubsection{Selimut Bintang $S_{3}$ pada graf $S_{6}$}

Banyak selimut $S_{3}$ pada graf $S_{n}$ adalah sebagai berikut :

$$
\begin{aligned}
\frac{n^{2}-3 n+2}{2} & =\frac{6^{2}-(3.6)+2}{2} \\
& =10
\end{aligned}
$$

Selanjutnya banyak selimut kelompok ke $-t$ dengan $1 \leq t \leq 4$ sebagai berikut :

- Banyak selimut kelompok ke -1 adalah $n-t-1=4$ dengan notasi selimut ke $-i$ untuk $1 \leq i \leq 4$ sebagai berikut :

$$
\begin{aligned}
& S_{3}^{1}=c v_{1}, c v_{2} \\
& S_{3}^{2}=c v_{1}, c v_{3} \\
& S_{3}^{3}=c v_{1}, c v_{4} \\
& S_{3}^{4}=c v_{1}, c v_{5}
\end{aligned}
$$

- Banyak selimut kelompok ke -2 adalah $n-t-1=3$ dengan notasi selimut ke $-i$ untuk $5 \leq i \leq 7$ sebagai berikut :

$$
\begin{aligned}
& S_{3}^{5}=c v_{2}, c v_{3} \\
& S_{3}^{6}=c v_{2}, c v_{4} \\
& S_{3}^{7}=c v_{2}, c v_{5}
\end{aligned}
$$

- Banyak selimut kelompok ke -3 adalah $n-t-1=2$ dengan notasi selimut ke $-i$ untuk $8 \leq i \leq 9$ sebagai berikut :

$$
\begin{aligned}
& S_{3}^{8}=c v_{3}, c v_{4} \\
& S_{3}^{9}=c v_{3}, c v_{5}
\end{aligned}
$$


- Banyak selimut kelompok ke -4 adalah $n-t-1=1$ dengan notasi selimut ke $-i$ untuk $10 \leq i \leq 10$ sebagai berikut :

$$
S_{3}^{10}=c v_{4}, c v_{5}
$$

Selanjutnya memberikan label titik dan sisi seperti pada Gambar 7 dan 8 .

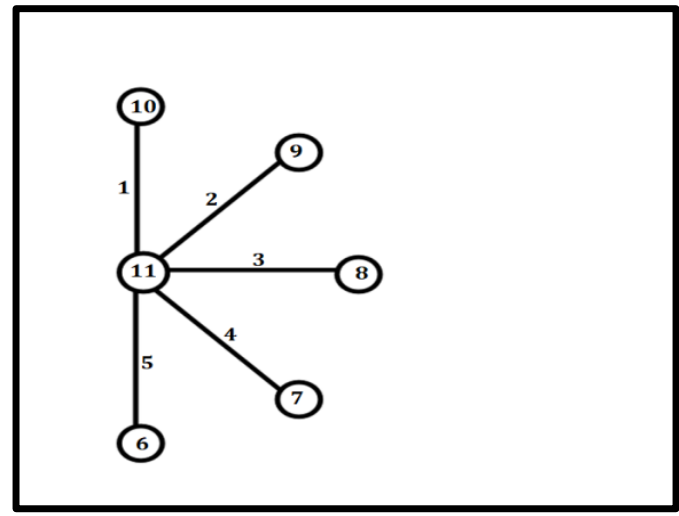

Gambar 7 : Pelabelan Total Selimut $S_{3}$-Ajaib Pada Graf $\mathbf{S}_{6}$

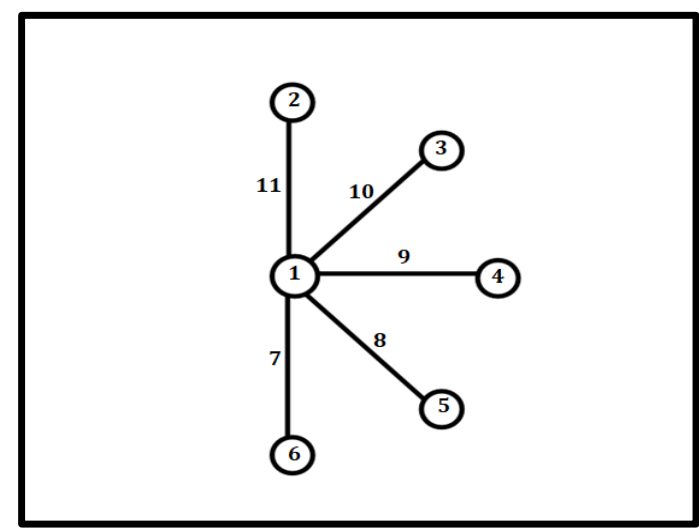

Gambar 8 : Pelabelan Total Selimut $S_{3}-$ Ajaib Super Pada Graf $\mathbf{S}_{\mathbf{6}}$

Perhatikan Gambar 7 dan Gambar 8 di atas bahwa titik diberi label dengan anggota himpunan untuk selimut ajaib $f(V)=\{1,2, \ldots, 2 n-1\}$ dan untuk selimut ajaib super $f(V)=\{1,2, \ldots, n\}$ dengan banyaknya titik $n=6$, sehingga diperoleh pelabelan total untuk selimut $S_{3}$ pada $S_{6}$ sebagai berikut :

- Pelabelan total ajaib

$$
\begin{array}{cc}
f(c)=11 & f\left(e_{1}\right)=1 \\
f\left(v_{1}\right)=10 & f\left(e_{2}\right)=2 \\
f\left(v_{2}\right)=9 & f\left(e_{3}\right)=3 \\
f\left(v_{3}\right)=8 & f\left(e_{4}\right)=4 \\
f\left(v_{4}\right)=7 & f\left(e_{5}\right)=5 \\
f\left(v_{4}\right)=6 &
\end{array}
$$

- Pelabelan total ajaib super

$$
\begin{array}{rlrl}
f(c)=1 & f\left(e_{1}\right)=11 \\
f\left(v_{1}\right)=2 & & f\left(e_{2}\right)=10
\end{array}
$$




$$
\begin{array}{cc}
f\left(v_{2}\right)=3 & f\left(e_{3}\right)=9 \\
f\left(v_{3}\right)=4 & f\left(e_{4}\right)=8 \\
f\left(v_{4}\right)=5 & f\left(e_{5}\right)=7 \\
f\left(v_{4}\right)=6 &
\end{array}
$$

Setelah diberikan label titik dan sisi, kemudian menghitung bobot untuk setiap selimut $S_{3}$ pada $S_{6}$ seperti berikut :

\section{- Pelabelan total ajaib}

Kelompok ke -1 untuk $1 \leq i \leq 4$ sebagai berikut :

$$
\begin{aligned}
W_{1}\left(S_{3}^{1}\right) & =f(c)+f\left(v_{1}\right)+f\left(v_{2}\right)+f\left(c v_{1}\right)+f\left(c v_{2}\right) \\
& =11+10+9+1+2 \\
& =33 \\
W_{2}\left(S_{3}^{2}\right) & =f(c)+f\left(v_{1}\right)+f\left(v_{3}\right)+f\left(c v_{1}\right)+f\left(c v_{3}\right) \\
& =11+10+8+1+3 \\
& =33 \\
W_{3}\left(S_{3}^{3}\right) & =f(c)+f\left(v_{1}\right)+f\left(v_{4}\right)+f\left(c v_{1}\right)+f\left(c v_{4}\right) \\
& =11+10+7+1+4 \\
& =33 \\
W_{4}\left(S_{3}^{4}\right) & =f(c)+f\left(v_{1}\right)+f\left(v_{5}\right)+f\left(c v_{1}\right)+f\left(c v_{5}\right) \\
& =11+10+6+1+5 \\
& =33
\end{aligned}
$$

Kelompok ke -2 untuk $5 \leq i \leq 7$ sebagai berikut :

$$
\begin{aligned}
W_{5}\left(S_{3}^{5}\right) & =f(c)+f\left(v_{2}\right)+f\left(v_{3}\right)+f\left(c v_{2}\right)+f\left(c v_{3}\right) \\
& =11+9+8+2+3 \\
& =33 \\
W_{6}\left(S_{3}^{6}\right) & =f(c)+f\left(v_{2}\right)+f\left(v_{4}\right)+f\left(c v_{2}\right)+f\left(c v_{4}\right) \\
& =11+9+7+2+4 \\
& =33 \\
W_{7}\left(S_{3}^{7}\right) & =f(c)+f\left(v_{2}\right)+f\left(v_{5}\right)+f\left(c v_{2}\right)+f\left(c v_{5}\right) \\
& =11+9+6+2+5 \\
& =33
\end{aligned}
$$

Kelompok ke -3 untuk $8 \leq i \leq 9$ sebagai berikut :

$$
\begin{aligned}
W_{8}\left(S_{3}^{8}\right) & =f(c)+f\left(v_{3}\right)+f\left(v_{4}\right)+f\left(c v_{3}\right)+f\left(c v_{4}\right) \\
& =11+8+7+3+4 \\
& =33 \\
W_{9}\left(S_{3}^{9}\right) & =f(c)+f\left(v_{3}\right)+f\left(v_{5}\right)+f\left(c v_{3}\right)+f\left(c v_{5}\right) \\
& =11+8+6+3+5 \\
& =33
\end{aligned}
$$

Kelompok ke -4 untuk $10 \leq i \leq 10$ sebagai berikut :

$$
\begin{aligned}
W_{10}\left(S_{3}^{10}\right) & =f(c)+f\left(v_{4}\right)+f\left(v_{5}\right)+f\left(c v_{4}\right)+f\left(c v_{5}\right) \\
& =11+7+6+4+5 \\
& =33
\end{aligned}
$$

- $\quad$ Pelabelan total ajaib super

Kelompok ke -1 untuk $1 \leq i \leq 4$ sebagai berikut :

$$
\begin{aligned}
W_{1}\left(S_{3}^{1}\right) & =f(c)+f\left(v_{1}\right)+f\left(v_{2}\right)+f\left(c v_{1}\right)+f\left(c v_{2}\right) \\
& =1+2+3+11+10 \\
& =27 \\
W_{2}\left(S_{3}^{2}\right) & =f(c)+f\left(v_{1}\right)+f\left(v_{3}\right)+f\left(c v_{1}\right)+f\left(c v_{3}\right) \\
& =1+2+4+11+9 \\
& =27 \\
W_{3}\left(S_{3}^{3}\right) & =f(c)+f\left(v_{1}\right)+f\left(v_{4}\right)+f\left(c v_{1}\right)+f\left(c v_{4}\right) \\
& =1+2+5+11+8
\end{aligned}
$$




$$
\begin{aligned}
& =27 \\
W_{4}\left(S_{3}^{4}\right) & =f(c)+f\left(v_{1}\right)+f\left(v_{5}\right)+f\left(c v_{1}\right)+f\left(c v_{5}\right) \\
& =1+2+6+11+7 \\
& =27
\end{aligned}
$$

Kelompok ke -2 untuk $5 \leq i \leq 7$ sebagai berikut :

$$
\begin{aligned}
W_{5}\left(S_{3}^{5}\right) & =f(c)+f\left(v_{2}\right)+f\left(v_{3}\right)+f\left(c v_{2}\right)+f\left(c v_{3}\right) \\
& =1+3+4+10+9 \\
& =27 \\
W_{6}\left(S_{3}^{6}\right) & =f(c)+f\left(v_{2}\right)+f\left(v_{4}\right)+f\left(c v_{2}\right)+f\left(c v_{4}\right) \\
& =1+3+5+10+8 \\
& =27 \\
W_{7}\left(S_{3}^{7}\right) & =f(c)+f\left(v_{2}\right)+f\left(v_{5}\right)+f\left(c v_{2}\right)+f\left(c v_{5}\right) \\
& =1+3+6+10+7 \\
& =27
\end{aligned}
$$

Kelompok ke -3 untuk $8 \leq i \leq 9$ sebagai berikut :

$$
\begin{aligned}
W_{8}\left(S_{3}^{8}\right) & =f(c)+f\left(v_{3}\right)+f\left(v_{4}\right)+f\left(c v_{3}\right)+f\left(c v_{4}\right) \\
& =1+4+5+9+8 \\
& =27 \\
W_{9}\left(S_{3}^{9}\right) & =f(c)+f\left(v_{3}\right)+f\left(v_{5}\right)+f\left(c v_{3}\right)+f\left(c v_{5}\right) \\
& =1+4+5+9+7 \\
& =27
\end{aligned}
$$

Kelompok ke -4 untuk $10 \leq i \leq 10$ sebagai berikut :

$$
\begin{aligned}
W_{10}\left(S_{3}^{10}\right) & =f(c)+f\left(v_{4}\right)+f\left(v_{5}\right)+f\left(c v_{4}\right)+f\left(c v_{5}\right) \\
& =1+5+6+8+7 \\
& =27
\end{aligned}
$$

Dari penjumlahan semua label titik dan sisi yang memuat selimut $S_{3}$ pada graf $S_{n}$ dengan $4 \leq n \leq 6$ di peroleh suatu konstanta yang sama pada setiap selimut $S_{3}$ di masingmasing $S_{n}$ yaitu untuk $S_{3}, S_{4}$ konstanta ajaib nya 21 dan konstanta ajaib supernya 19, untuk $S_{3}, S_{5}$ konstanta ajaib nya 27 dan konstanta ajaib supernya 23 , untuk $S_{3}, S_{6}$ konstanta ajaib nya 33 dan konstanta ajaib supernya 27. Graf $S_{n}$ memenuhi Teorema 1 dan Teorema 2 serta Definisi 2.1 yaitu pelabelan selimut ajaib dan pelabelan selimut ajaib super.

\section{KESIMPULAN}

Berdasarkan hasil penelitian yang telah dilakukan, dapat disimpulkan bahwa graf bintang $S_{n}$ memiliki pelabelan selimut bintang $S_{3}$ - ajaib untuk $n \geq 4$ dengan konstanta ajaib $6 n-3$. Dan memiliki pelabelan selimut bintang $S_{3}$ - ajaib super untuk $n \geq 4$ dengan konstanta ajaib $4 n+3$.

\section{DAFTAR PUSTAKA}

[1]. Cunningham, D., Vertex-magic, Electronic Journal Of Undergraduate Mathematics $9: 1-20$, 2004.

[2]. Enomoto, H., Super Edge-magic Graph, Jurnal of Mathematics Vol. 34, No. 2, 105-109, (http://web.thu.edu.tw/wang/www/SEM_98.pdf), 1998, diakses tanggal 22 juni 2015 pukul 16.26 WITA.

[3]. Gallian, A. J., A Dynamic Survey of Graph Labeling, U.S.A : University of Minnesota Duluth, 19, 2016, 150-153. 
[4]. Guitierrez, A., dan Llado A., Magic coverings, J. Combin. Math. Combin, Comput, 2005, 55 : 43-56.

[5]. Irawati, D., Pelabelan Total Sisi Ajaib Super Pada Graf Bintang, journal mathematics UNAND. Vol. 2, No. 1, 2013, 85-89.

[6]. Jayanthi, P., Salvagopal, P., dan Sundaram, S. Soma., Some $C_{3}$ - Supermagic Graphs, Until. Math., 2013, 89, 357-366.

[7]. Kotzig, A., and Rosa, A., Magic Valuations of finite Graphs, Canad. Math. Bull, 13, 1970, 451461.

[8]. Llado, A., and Moragas, J., Cycle-megic graphs, Discrete Math. 307 : 23, 2007, 2925-2933

[9]. Maryati, T.K., Baskoro, E.T., and Salman, A.N.M., $P_{h}$ - supermagic labelings of some treess, J. Combin. Math. Combin. Comput, 2008, 65 : 197-207.

[10]. Maryati, T.K., Salman, A. N. M., Baskoro, E.T., and Irawati., On The Path-(super) Magicness of a Cycle With Some Pendants, Until Math., 96, 2015, 319-330.

[11]. Ngurah, A. A. G., Salman, A.N.M., and Susilowati, L., H-supermagic labelings of graphs. Discrete Math. $310: 8,2008,1293-1300$.

[12]. Ray, S.S., Graph Theorywith Algortthms and its Applications, 2013, Springer India.

[13]. Roswitha, M., Baskoro, E. T., Maryati, T. K., Kurdhi, N. A., and Susanti, I., Father Results on Cycle-Supermagic labeling, AKCE Int. J. Graphs Comb., 10(2), 2003, 211-220.

[14]. Selvagopal, P., and Jayanthi. P., On $C_{k}-$ Supermagic Graphs, International Journal Mathematics and Scientific Computing, Sci., 3, 2008, 25-30.

[15]. Sudarsana, I. W., Noviana, Musdalifah, S., dan Kasim, A. A., Pelabelan Total Sisi Ajaib Super (TSAS) pada Gabungan Graf Bintasng Ganda dan Lintasan, Journal of Natural Science, 10(1), 2013, 1-10. 